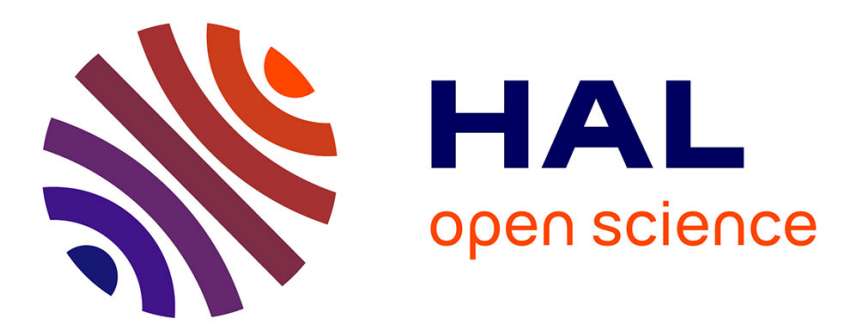

\title{
Supporting decision for environment-friendly practices in the agri-food sector
}

Rallou Thomopoulos, Bernard Moulin, Laurent Bedoussac

\section{To cite this version:}

Rallou Thomopoulos, Bernard Moulin, Laurent Bedoussac. Supporting decision for environmentfriendly practices in the agri-food sector: When argumentation and system dynamics simulation complete each other. International Journal of Agricultural and Environmental Information Systems, 2018, 9 (3), pp.1-21. 10.4018/IJAEIS.2018070101 . hal-01837532

\section{HAL Id: hal-01837532 https://hal.science/hal-01837532}

Submitted on 26 May 2020

HAL is a multi-disciplinary open access archive for the deposit and dissemination of scientific research documents, whether they are published or not. The documents may come from teaching and research institutions in France or abroad, or from public or private research centers.
L'archive ouverte pluridisciplinaire HAL, est destinée au dépôt et à la diffusion de documents scientifiques de niveau recherche, publiés ou non, émanant des établissements d'enseignement et de recherche français ou étrangers, des laboratoires publics ou privés. 


\title{
Supporting Decision for Environment- Friendly Practices in the Agri-Food Sector: When Argumentation and System Dynamics Simulation Complete Each Other
}

\author{
Rallou Thomopoulos, INRA Iate / INRIA GraphIK, Montpellier, France \\ Bernard Moulin, Laval University, Quebec, Canada \\ Laurent Bedoussac, AGIR, Université de Toulouse, Castanet-Tolosan, France
}

\begin{abstract}
High-level decision-making, such as policy making, needs to take into account the often-conflicting interests of different stakeholders with the goal of finding solutions to provide trade-offs and build consensus towards the adoption of so-called win-win solutions. In this article, the authors suggest that using a modeling and simulation approach would greatly enrich the deliberation process. The authors propose a systematic method to assess possible options, based on the complementarity of argumentation modeling and system dynamics (SD) simulation, in conjunction with field experimentation. As a practical application, the authors assess various options available to agri-food chain stakeholders when considering the adoption of cereal-legume intercrops as an alternative to sole crops. Taking advantage of the argument analysis, SD simulations are used to: 1) compare different cultural strategies available to farmers in current operating, market and regulatory conditions; 2) propose plausible what-if scenarios anticipating technological progress, and exploring the impact of adopting potential incentives and dissuasive regulatory measures.
\end{abstract}

\section{KEYWORDS}

Alternative, Cereals, Explanatory Method, Intercrop, Legumes, Model Integration, Option, Scenario

\section{INTRODUCTION}

It is recognized that collaborative modeling approaches can create value in agri-food chains (Filippi \& Chapdaniel, 2016) in which numerous actors or stakeholders interact and participate in coordinated activities (Handayati et al., 2015) to create and offer a particular good or service. However, agri-food chains are complex systems in which stakeholders are prone to tensions, conflicts, policy threats and vertical integration pressure (Campbell, 2004; Balmann et al., 2006). Approaches such as consensus building (Burgess et al., 2003; Campbell, 2004) have been proposed to help increase stakeholders' awareness of critical situations in agri-food chains (usually in deliberation processes related to policy making) and to better understand the different positions and viewpoints of the different involved parties. 


\subsection{Consensus Building}

It is also acknowledged that stakeholders would be in a better position to make compromise if they were willing to reach a consensus-based solution and if they clearly understood the positions of the different parties. Consensus building is a conflict-resolution process mainly used to settle complex, multiparty issues (Gray, 1989). Since the 1980s, it has become widely used in the environmental and public policy arena. The process allows various stakeholders (parties with an interest in the problem or issue) to work together to develop a mutually acceptable solution (Burgess et al., 2003). The consensus-building process helps stakeholders to establish a common understanding of the attended situation (process which is often called 'situation awareness' (Adam et al., 1995; Endsley, 1995) and to create a framework for developing a solution that works for everyone.

\subsection{Argumentation Modeling and Visualization Approaches}

Gray (1989) showed that problems that are best addressed using a consensus-building approach tend to share some general characteristics such as: 1) The problems are ill-defined, or there is disagreement about how they should be defined; 2) Several stakeholders have a vested interest in the problems and are interdependent; 3) Stakeholders may have different levels of expertise and different access to information about the problems; 4) The problems are often characterized by technical complexity and scientific uncertainty; 5) Incremental or unilateral efforts to deal with the problems typically produce less than satisfactory solutions; 6) Existing processes for addressing the problems have proved insufficient and may even exacerbate them.

Interestingly, van Bruggen et al. (2003) demonstrate the value of using Computer-Supported Argumentation Visualization (CSAV) to tackle ill-structured problems, which share a large number of characteristics with the problems addressed by consensus-building approaches (Gray, 1989). The main reason is that solving ill-structured problems results from an argumentative process starting from informal reasoning (van Bruggen et al., 2003) and requires building an argumentation structure which consists, minimally, of a claim with support (e.g. evidential reasoning). Evaluation of the arguments cannot be carried out in terms of whether any argument is right or wrong, but requires the evaluator to make use of other criteria such as acceptability of the claim, and the quality of the argumentation which is assessed by taking counter-arguments into account. Argument-based and agent-based modeling approaches have recently been proposed to enhance stakeholder interactions in agrifood chains (Bourguet et al., 2013; Thomopoulos et al., 2015; Croitoru et al., 2016).

\subsection{The Role of Simulation}

Although modeling argument structures and explaining argument relationships to stakeholders is quite helpful in helping involved parties understand each other's positions and facilitate the deliberation process (Bourguet et al., 2013), stakeholders have no means to anticipate the impacts of adopting the debated solutions, let alone to compare them. This is where using modeling approaches and simulation software would greatly enrich the deliberation process. As an example of such modeling and simulation approaches, system dynamics (SD) has been widely used for the past fifty years to model complex socio-economic systems and to simulate their behavior and evolution in a large variety of domains in almost any discipline involving policy making and strategic planning (Hirsch et al., 2010; Ghaffarzadegan et al., 2011; Marshall et al., 2015). For example, SD has been used to assess food system vulnerabilities (Stave et al., 2015). However, our literature review has not found any DSS method or software that integrates argumentation modeling/reasoning and visualization techniques and tools with SD analysis and simulation software.

\subsection{Aim and Structure of the Paper}

The objective of our work is to develop an integrated approach and to create a decision support software to help stakeholders create a common situation awareness and possibly build consensus, 
while taking into account the conflicting viewpoints of the involved parties. The proposed approach is based on complementary modeling and simulation techniques, namely argumentation modeling and visualization, SD modeling and simulation. In this paper we present the main steps of the proposed approach and show its application in a case study where argumentation modeling and SD simulation are used to assess and compare various options available to farmers for cereal-legume intercrops with respect to the corresponding sole crop alternatives. The paper is organized as follows. Section 3 presents the agri-food case study. Section 4 details the methodological steps of our approach. Section 5 presents its application on the case study.

\section{CASE STUDY}

\subsection{The Intercropping Debate}

Intercropping (IC) is the simultaneous growth of two or more species in the same field during a significant period of time. It agrees with ecological principles. This practice is particularly suited in low nitrogen input systems where it optimizes the use of $\mathrm{N}$ resources through $\mathrm{N} 2$ fixation of legumes leading to improved and stabilized yields and increased cereal protein content (Bedoussac et al., 2015). Nevertheless, despite their numerous agronomic interests widely demonstrated, intercrops are still only slightly adopted by farmers, except for animal feeding and/or in organic farming. Indeed, the main stakeholders still question the potential economic advantage of intercropping because it depends on many factors such as the difference between crop prices, the cost of efficiently separating the grains, but also on the prices of chemical inputs and the amount of available subsidies.

A large number of arguments for and against cereal-legume intercropping have been expressed by the main stakeholders of the supply chain, notably in technical articles (Pelzer et al., 2014; PerfCom Project, 2012). Moreover, various aspects of intercropping have been discussed in a recent review (Bedoussac et al., 2015), including grain production, protein concentration, weed reduction, use of nitrogen and light resources, effects of low-input systems, crop rotation design, and economic benefits. In this context it is important to note that intercropping adoption is influenced by public and private interests. The ecological benefits of intercropping are of great importance when considering collective interest and related public decision making. However, they interfere with farmers' private interests which, first and foremost, depend on the economic viability of intercropping.

These observations motivated our research and led to our proposal for a deeper assessment of the situation based on: 1) the analysis of arguments put forward by different reliable stakeholder groups in favor or against the adoption of specific practices (that we will call 'options') or agricultural decisions by the main concerned actors (i.e. farmers); 2) the development of models to create scenarios that simulate how the available options/decisions might influence the actors' operations; 3 ) the comparison of the outcomes of these scenarios to inform the main stakeholders' decision process (i.e. farmers and public policy makers) with respect to the debated issues. Therefore, in this article, we put the emphasis on farmers' economic interest by considering how their gross margin can evolve under several hypotheses. Among these hypotheses, we consider public interventions (by means of incentive or dissuasive measures) that express the willingness of public authorities to take into account the economic viability of intercropping for farmers, which is a major bottleneck for intercropping adoption. In the present study we specifically address the case of intercropping of durum wheat and legumes, since it represents an alternative to producing: 1) durum wheat as a sole crop, usually fertilized with large amounts of nitrogen and pesticides and 2) grain legumes that can reduce the dependency on nitrogen, but whose cultivated surface has strongly decreased during the last decades, notably because of their instable yields. 


\subsection{Agronomic Experimentation of Different Cultural Alternatives}

Since most farms operating at an industrial scale practice extensive cereal sole-crop, there is a lack of practical and historical data documenting the outcomes of cereal legume intercropping. This lack of data was an obstacle to the scientific examination of important arguments related to cultural practices put forward in the intercropping debate. In this context, a field experiment was conducted in 20072008 by one of our team members to assess different intercropping strategies, taking into account different cultural possibilities that can plausibly be chosen by farmers. The main objective of the experiment was to compare intercropping efficiency to sole cropping strategies in order to produce durum wheat with sufficient grain protein concentration in low input systems.

In this paper we only compare one of the tested intercropping strategies with the sole cropping strategy that will be used as a reference base. Here are the technical details of these strategies:

- Durum wheat (cv Neodur) intercropped with winter pea (cv. Lucy) is sown in one time to reduce sowing cost. The two species were sown at half of their sole crop density ( 168 grain. $\mathrm{m}^{-2}$ for wheat and 36 grain. $\mathrm{m}^{-2}$ for pea). According to (Bedoussac and Justes, 2010), $35 \mathrm{~kg}$ mineral N.ha ${ }^{-1}$ were applied at the 'visible flag leaf' wheat stage corresponding to the beginning of pea grain filling since this late supply allows to improve the wheat grain protein content without affecting the legume yield. Chemical treated seeds were used altogether with one application of herbicide before emergence, but no insecticide and no fungicide were applied.

- Durum wheat low input sole crop (cv. Neodur) sown at 336 grain. $\mathrm{m}^{-2}$ and fertilised with $75 \mathrm{~kg}$ mineral N.ha ${ }^{-1}\left(40 \mathrm{~kg} \mathrm{~N} \cdot \mathrm{ha}^{-1}\right.$ at stage ear $1 \mathrm{~cm}$ of wheat and $35 \mathrm{~kg} \mathrm{~N} \cdot \mathrm{ha}^{-1}$ at the 'visible flag leaf' wheat stage). Treated seeds were used altogether with one herbicide before emergence and two fungicides to prevent wheat diseases.

Grain yield was measured at harvest time and economical evaluation was performed considering mechanical costs: $60 €$. ha $^{-1}$ for plowing; $93 €$. ha $^{-1}$ for soil preparation; $40 €$. ha ${ }^{-1}$ for sowing the sole cropped wheat and $80 €$. ha $^{-1}$ for the two passes in the intercrop; $12 € . \mathrm{ha}^{-1}$ for each spraying treatment (12€.ha ${ }^{-1}$ for the intercrop and $36 € \cdot$ ha $^{-1}$ for the sole cropped wheat); $10 €$.ha ${ }^{-1}$ for each nitrogen application ( $10 € \cdot \mathrm{ha}^{-1}$ for the intercrop and $20 € \cdot$ ha $^{-1}$ for the sole cropped wheat); $80 €$. ha $^{-1}$ for the harvest; $63 €$. ha $^{-1}$ for straw incorporation done in three passes; $4 € . \mathrm{t}^{-1}$ for transport and $50 € . \mathrm{t}^{-1}$ to separate the grains of the intercrops.

Operational costs included: $110 € . \mathrm{ha}^{-1}$ for seeds in both sole crop and intercrop; $1.33 € . \mathrm{kg}^{-1}$ of nitrogen ( $47 €$. ha $^{-1}$ for the intercrop and $100 €$. ha $^{-1}$ for the sole cropped wheat); $23 €$. ha - $^{-1}$ for herbicide in both sole crop and intercrop and $88 € \cdot \mathrm{ha}^{-1}$ for fungicide treatments in the sole cropped wheat.

The estimated crop prices were based on references obtained from collectors on average for the 2004-2007 period: $145 € . \mathrm{t}^{-1}$ for the wheat and $130 € . \mathrm{t}^{-1}$ for the pea. We also took into account that wheat price depends on its quality (grain protein content, specific weight and vitrousness) leading to a final price of $141.5 € . \mathrm{t}^{-1}$ for the intercropped wheat and $139.7 € . \mathrm{t}^{-1}$ for the sole cropped wheat. Finally the subsidies included: $300 € . \mathrm{ha}^{-1}$ for the Single Farm Payment in both sole cropped wheat and intercrop; $75 €$. ha ${ }^{-1}$ for unirrigated surface subsidy; $46 €$. ha $^{-1}$ for the durum wheat subsidy in both sole cropped wheat and intercrop and $26 € \cdot \mathrm{ha}^{-1}$ for the durum wheat quality subsidy only in the sole crop.

\subsection{Experimentation Results}

The intercrop grain yield was 4.45 t.ha $^{-1}$ including 1.02 t.ha $^{-1}$ of pea. It was lower than the 5.81 t.ha $^{-1}$ of the sole cropped wheat. No significant difference was found in the grain protein content with $13.5 \%$ for the sole cropped wheat and $13.3 \%$ when intercropped. However, we must remember that the intercrop received two times less nitrogen than the sole cropped wheat. This result agrees with other results in the literature (Bedoussac et al., 2016), confirming that intercropping is more efficient than sole cropping in low nitrogen input systems. 
Let us emphasize that the grain yield advantage of intercropping is not the only element taken into account by farmers when deciding to adopt or discard an intercropping strategy. Indeed, their decision relies on a broader view of the economic equation, taking into account a number of other elements such as operational costs, selling rates and the (non-)availability of governmental subsidies, to name a few.

As shown in the next section, these experimental data will be used to set some parameters of the SD models which are developed to simulate scenarios enacting different variations of the intercropping strategies that may be adopted by farmers.

\section{A NEW APPROACH BASED ON ARGUMENTATION AND NUMERICAL SIMULATION}

In practice, stakeholders have no means to anticipate the impacts of adopting any of the debated solutions. To this end, we suggest that using modeling approaches and simulation software would greatly enrich the deliberation process. Among the main interests of choosing System Dynamics in this work, let us mention: (1) explicit formalization of all variables, with as consequence (2) formal link with the arguments made possible by the explanation of the variables, allowing (3) graphical visualization of the variables and (4) choice of the time step of the simulation that can be stopped at the chosen time, in order to (5) test scenarios immediately by varying the value of chosen variables.

In the context of the intercropping debate, we propose such an integrated approach to help farmers and public policy makers to assess different scenarios about measures that could promote cereal-legume intercrops with respect to the corresponding sole crop alternatives. In line with previous works related to the influence of public intervention in the agriculture sector (Casey et al., 1999; Chambers, 2002), we analyze and compare two scenarios, namely incentive versus dissuasive public policy measures, and conclude on an intermediate one, which can provide a fresh view of the intercropping debate.

The proposed method is composed of four main steps that are presented in this section.

\subsection{Setting the Objectives and Scope of the Study}

This step is composed of a number of sub-tasks, illustrated here on our case study:

- Objectives of the Study: 1. Identify obstacles that prevent farmers from adopting cereal-legume intercropping practices; 2 . Study regulation measures that could promote cereal-legume intercrops with respect to the corresponding sole crop alternatives.

- The Main Debated Issues: We call them the 'intercropping debate': 1. Ecological benefits of cereal-legume intercropping with respect to cereal sole crops; 2. Economic viability of intercropping under current farmers' operating conditions, cereal/legume market and (un-) availability of incentives/subsidies.

- Interested Stakeholders: Public Policy makers, Farmers' groups.

- Selected Actors: Farmers interested in adopting cereal-legume intercropping practices.

- Preliminary Characterization of the Selected Actors' Situation: Synthetic view of the farmer's financial situation through the analysis of the half-net margin.

- External Forces Influencing the Selected Actors' Situation: Markets for cereal and legumes, technological advances (for example efficient sorters for mixed grains), financial aids (i.e. incentives, subsidies), environmental and climatic conditions.

- Preliminary identification of options available to the selected actors:

- Main cultural options: 1. Durum wheat sole crop; 2. durum wheat and winter pea intercropping.

- Main commercialisation options: 1. Durum wheat market (the most attractive market, but depending on the quality of produced grains); 2. Winter pea market; 3 . Currently, no market 
for durum wheat and pea mixed grains for human consumption; 4. less attractive market for mixed grains for animal consumption.

- Identification of documentation and resources: Many papers and reports supporting or attacking either option, but no conclusive study or recommendation.

\subsection{Argument Collection and Selection of the Most Relevant ones Exploiting Argumentation Systems}

In order to better understand the intercropping debate we performed an extensive literature review (see Section 3.1) and carried out interviews with domain specialists to collect and organize the various arguments put forward by the different stakeholders and specialists. Then, the argument analysis was performed in four steps: 1. the main arguments in favor and against cereal-legume intercrops were identified; 2 . arguments were refined and structured in argument/option tables which establish a link decisions that the selected actors may make; 3 . the contents of the argument/option tables were displayed in the form of argumentation systems that can be evaluated in terms of coherence and completeness using the argumentation theory (Dung, 1995), which led us to select a sub-set of arguments that were deemed relevant in the context of our study; 4 . finally, we analysed the selected arguments to raise some hypotheses that can be plausibly considered when exploring different options available to farmers when adopting cereal-legume intercropping practices. These hypotheses are used to set parameter values in the numerical simulations.

\subsection{Numerical Simulations of Reference Scenarios}

To help stakeholders better understand how the choice of either cultural strategy may influence the situation of the selected actors (i.e. farmers), we propose to first develop a System Dynamics model (SD model) that emphasizes the main elements of the selected actors' situation. Then, we use the model to simulate scenarios corresponding to the options (i.e. cultural practices) that may be chosen by the selected actors. This step is divided into several subtasks:

- In order to model the selected actors' situation, identify the main variables that characterize their decision making process. Some of these variables may be under the actor's control, while other variables reflect the influence of external factors such as market price, costs of equipment and fertilizers.

- Create a SD model of the decision making process using these variables and taking into account their interactions. The SD model is then calibrated using well-known data sets. In the present study we used available historical data to compute the farmer's gross margin in the case of durum wheat sole crop using low nitrogen input.

- Select plausible technical hypotheses: Information from various sources (interviews with stakeholders, publicly available historical statistics, etc.) is used to identify: 1 . plausible hypotheses to set key external factors of the SD model (such as the market price for durum wheat and for peas); 2. plausible options for the selected actors that are expressed in terms of values assigned to variables under the actors' control in the SD model. Having set these hypotheses, the SD model can be adjusted.

- Run SD simulations: Using the SD model and data obtained from the agronomic experimentation, we carried out simulations for the two main cultural strategies that are discussed in the intercropping debate: 1. durum wheat sole-crop and 2. durum wheat and winter pea intercropping. The scenarios that result from these simulations are called reference scenarios since they are used as a basis for the comparison of the results of What-if scenarios presented in the next sub-section. 


\subsection{What-If Analysis and Conclusion of the Study}

The reference scenarios are used to compare, from the farmer's point of view, the outcomes of applying either cultural alternatives, given the conditions currently prevailing in the market, in the industry and the (non-)existence of public incentives and subsidies. The objective of the What-if analysis step is to explore how changes occurring in some of these conditions may influence the outcomes of applying either cultural alternative. Here are the sub-tasks proposed to carry out the what-if analysis.

- Select Plausible What-if Hypotheses: We suggest to first set what we call What-if hypotheses that can formalize: 1. plausible trends of certain external forces (such as technological innovation and related decrease of equipment costs); 2. certain measures that can be plausibly adopted by public authorities to promote cereal-legume intercrops.

- Perform What-if Scenarios: The SD model is adjusted according to each chosen What-if hypothesis and run to simulate the corresponding What-if scenario. Indeed, different What-if scenarios can be explored. They correspond to variations of the SD model with different value combinations of the above mentioned external factors and controlled variables. The final state of a scenario is expressed in terms of variables that represent the outcome of the scenario on the selected actor's situation.

- Conclude: The comparison of the final states of the What-if scenarios allows for the assessment of the different options available to the selected actors (i.e. farmers) and influential stakeholders (i.e. public authorities), while taking into account the different hypotheses that were set. On the basis of such a comparison, analysts can draw conclusions in relation to the debated issues and propose recommendations to the stakeholders interested in the study.

\section{APPLYING THE ARGUMENTATION AND SIMULATION APPROACH ON THE CASE STUDY}

In this section we present and briefly justify the argumentation framework that we use in our approach. Then, we illustrate how our approach (Section 4) has been applied to the case study (Section 3) by presenting and discussing the main results that were obtained.

\subsection{A Few Words About the Argumentation Formalism Used in this Approach}

Let us recall that an argumentation system is usually represented as an oriented graph where nodes are arguments and edges are attack relations between arguments. Considering Dung's seminal work on argumentation (1995), an argument and the attack relation are abstract and can be instantiated and defined in different ways in different contexts (Walton, 2009). Dung himself stated: “....an argument is an abstract entity whose role is solely determined by its relations to other arguments. No special attention is paid to the internal structure of the arguments..." For example, an argument can be a set of statements composed of a conclusion and at least one premise, linked by an inference or a logical relation. Attacking an argument can be achieved in different ways: 1. by raising doubts about its acceptability through critical questions; 2 . by questioning its premises; or 3 . by putting forward that the premises are not relevant to the conclusion. Still another way to attack an argument is to present an argument with an opposing conclusion. In this latter case, when arguments support different conclusions, an attack relation is said to exist.

Although theoretically sound, applying Dung's framework in an industrial context is not straightforward; one of the initial difficulty being how to practically define an argument in order to reflect stakeholders' statements in a debate. Unfortunately, there is still no general model that can be used to formalize a natural argument (i.e. an argument stated by a stakeholder during a discussion in natural language) and input in an abstract argumentation framework in a real decision-making context. Quoting Baroni and Giacomin (2009): "While the word 'argument' may recall several 
intuitive meanings, like the ones of 'line of reasoning leading from some premise to a conclusion' or of 'utterance in a dispute', abstract argument systems are not (even implicitly or indirectly) bound to any of them: an abstract argument is not assumed to have any specific structure but, roughly speaking, an argument is anything that may attack or be attacked by another argument..." Indeed, the structure of an abstract argument do not correspond to the intuitive understanding of what an argument is; and the notion of "attack between arguments" does not have a natural and direct correspondence to practical expressions used by stakeholders when debating. Moreover, representing arguments as an oriented graph can be a difficult task for stakeholders: when the number of arguments and/or attacks is large, the graph becomes illegible and difficult to interpret by stakeholders.

In our project, we needed to find a practical way of defining arguments that are used in the process of decision making. In such a context, arguments can be intuitively thought of as being statements to support, contradict, or explain opinions or decisions (Amgoud \& Prade, 2009). More precisely, in decisional argumentation frameworks (Ouerdane et al., 2010), the argument definition is enriched additional features, namely the decision (also referred to as 'action', 'option' or 'alternative') and the goal (also referred to as 'target'). In other studies arguments are also associated with specific actors. An application of a decision-oriented argumentation framework to a real-life problem concerning food policy can be found in Bourguet et al. (2013), where a recommendation regarding the provision of whole-grain bread was analyzed a posteriori. In this case, each argument is associated with the action it supports. Based on the above rationale, we chose to specify an argument as a tuple composed of an identifier, a type, an explanation, a criterion, an option and a sub-option. Formally:

An argument is a tuple $\mathrm{a}=(\mathrm{I} ; \mathrm{T} ; \mathrm{E} ; \mathrm{C} ; \mathrm{O} ; \mathrm{S})$ where:

- I Is the identifier of the argument;

- $\mathrm{T}$ is the type of the argument (with values in favour or against an option);

- $\quad \mathrm{E}$ is the explanation underlying the argument;

- $\mathrm{C}$ is the criterion which the argument relies on;

- $\quad$ is the option (i.e. the decision) considered by the argument;

- $\mathrm{S}$ is the sub-option considered by the argument.

For any argument $a$, we denote by $I(a), T(a), E(a), C(a), O(a), S(a)$ respectively the identifier, the type, the explanation, the criterion, the option and the sub-option of argument $a$.

As an illustration Table 1 displays the set of arguments considered in our case study. More details about how our argument model is applied to the case study are provided in Sections 5.2 and 4.3.

Now, let us consider the attack relation. In structured argumentation (i.e. logic-based argumentation frameworks where arguments are obtained as instantiations over an inconsistent knowledge base) three kinds of attacks have been defined: undercut, rebut and undermine (Besnard \& Hunter, 2008). The intuition of these attack relations is either to counter the premise of the opposing argument ('undercut'), the conclusion ('rebut') or to attack the logical steps that allowed the inference between the argument's premise and conclusion (undermine). In abstract argumentation the set of attacks is simply considered as provided a priori. Another possibility that can be considered is to enhance the argumentation framework with a set of preferences, expressed for instance as weights representing uncertainty. In our project we needed to choose a practical way to define the attack relation. Considering the reality of stakeholders' debates and our model to formalize arguments, we chose to model the attack relation in the following way. Attacking an argument is achieved by: 1) raising doubts about the acceptability of the sub-option it supports and 2) expressing a counter-argument after it, chronologically speaking. Formally, we consider the following attack relation:

Let $a$ and $b$ be two arguments. We say that $a$ attacks $b$ if and only if the following three conditions are satisfied: 
1. $O(a)=O(b)$;

2. $\quad[S(a)=S(b)$ and $T(a) \neq T(b)]$ or $[S(a) \neq S(b)$ and $T(a)=T(b)]$;

3. $a$ was expressed after $b$.

The first condition expresses that arguments $a$ and $b$ support the same option. The second condition expresses that $a$ and $b$ are one in favour and the other against the same sub-option, or both in favour (resp. against) different sub-options. The third condition avoids obtaining a symmetric attack relation by taking into account the time when each argument has been expressed, hence we consider the 'chronology' of arguments.

Considering these notations, we present in the following sub-sections how our approach has been applied to the case study presented in Section 3.

\subsection{Argument Collection and Structuration}

The collection of pro and con argument highlighted different categories of concerns. As an example, the hindrance to the development of cereal-legume intercrops included important categories of arguments: 1) legal concerns; 2) technical issues subdivided into calendar-related and equipmentrelated considerations; 3 ) commercial opportunities and 4) doubts about the long-term viability within rotations. Using the results of the argument collection, we recommend to build argument tables that show which arguments are used to debate about possible decisions (also denoted "options"); i.e. which arguments support, or are against, each option (or sub-set of options). Identifying in the set of arguments the potential options that are available to the selected actors is an important activity of the argument analysis step. Indeed, this enables the analyst to establish an explicit link between the arguments and important actions/decisions that are parts of the selected actors' decision process. As an example, we can identify certain options available to farmers such as: 'With sorting' or 'Without sorting' [the mixed harvest], and if the sorting option has been chosen, which [sorting] technique to use, when (at harvest time, post-harvest) and where [at which scale]. As an illustration, Table 1 shows a subset of arguments that are in favor or against 3 options available to farmers: (1) no sorting; (2) sorting at harvest time; (3) after harvest. In the latter case, the sorting may be efficient or classic, and both options are considered.

In Table 1 we see that each argument is displayed with: an identifier ('ID'); an Argument type ('+' if it is in favor; '-' if it is against the option); an 'Explanation' (a short sentence summing up the argument); and a 'Criterion' which categorizes the argument (as for example 'economic' or 'technical'). The options appear on lines of the table (printed in bold), as for example 'No sorting', 'Sorting at harvest time' and 'After-harvest sorting'. Because arguments may support or attack a combination of options, we may also need to display sub-options of a given option. For example, under the 'No sorting' option we see in Table 1 three alternative sub-options: 'Commercialization of the mix', 'Own consumption' and 'Commercialization of the mix for animal feed'. This means that these entries display arguments in favor and against each combination of the option and its sub-options. Indeed, in certain cases sub-options may have 'sub-sub-options' and chains of options can be displayed in a tree-like form. We discovered that organizing the table in this way puts the emphasis on the existence of portions of tree structures that were derived from the analysis of the arguments initially collected from various sources. This is an innovative way of representing sets of arguments in a tabular form that establishes a link between the arguments and chains of decisions that the selected actors may make in their decision process.

Once the argument/option tables formalized, we can build networks of arguments in order to analyse the coherence of the arguments supporting the options available to the selected actors. Networks of arguments constitute a graphical representation of argumentation systems that have been studied for many years by the artificial intelligence community, expanding Dung's seminal proposal (Dung, 1995). An argument system formalizes arguments and counter-arguments, using a binary relation called " attack" which reflects conflicts among arguments. An argumentation system is thus 
Table 1. Argument/Option table structuring the arguments debating the following options: (1) no sorting; (2) sorting at harvest time or (3) after harvest

\begin{tabular}{|c|c|c|c|}
\hline ID & $\begin{array}{l}\text { Argument } \\
\text { type }\end{array}$ & Explanation & Criterion \\
\hline \multicolumn{4}{|c|}{ No sorting } \\
\hline & \multicolumn{3}{|c|}{ Commercialization of the mix } \\
\hline 1 & - & Mixed grains are not economically viable, by lack of market opportunities & $\begin{array}{l}\text { Economic (added } \\
\text { value) }\end{array}$ \\
\hline \multirow[t]{2}{*}{2} & + & $\begin{array}{l}\text { Commercializing mixed grains is competitive, since the sorting step, which is very } \\
\text { costly, is avoided }\end{array}$ & Economic \\
\hline & \multicolumn{3}{|c|}{ Own consumption } \\
\hline 3 & + & Mixed grains can be consumed on the farm & Technical (ease of use) \\
\hline \multirow[t]{2}{*}{4} & - & $\begin{array}{l}\text { Own consumption is limited to small quantities and non-profit use, since no added } \\
\text { value is created }\end{array}$ & Economic \\
\hline & \multicolumn{3}{|c|}{ Commercialization of the mix for animal feed } \\
\hline 5 & + & Little sorting, or not at all, is required for animal feed & Technical (ease of use) \\
\hline 6 & - & $\begin{array}{l}\text { Market prices to commercialize mixed grains for animal feed are lower than for } \\
\text { human consumption, and possibly below cost }\end{array}$ & Economic \\
\hline 7 & - & $\begin{array}{l}\text { Product innovation is required to use mixed grains (e.g. durum wheat/pea couscous; } \\
\text { durum wheat/legume pasta) }\end{array}$ & Technical (feasibility) \\
\hline 8 & + & There are growing market opportunities for mixed grain products & Economic \\
\hline \multicolumn{4}{|c|}{ Sorting at harvest time } \\
\hline & \multicolumn{3}{|c|}{ Commercialization of separate grains } \\
\hline 9 & - & Dual combine harvesters are not available on the market currently & Technical \\
\hline 10 & + & Dual combine harvesters could be manufactured & Technical \\
\hline 11 & + & $\begin{array}{l}\text { The harvest can be achieved in two phases: a first run with a legume-setting of the } \\
\text { harvester, then a second run with a cereal-setting }\end{array}$ & Technical \\
\hline 12 & - & The two-phase option is costly and thus unlikely & Economic \\
\hline \multicolumn{4}{|c|}{ After-harvest Sorting } \\
\hline & \multicolumn{3}{|c|}{ Efficient Sorting } \\
\hline 13 & + & Efficient sorting technology exists & Technical \\
\hline 14 & - & Efficient sorting technology is costly & Economic \\
\hline \multirow[t]{2}{*}{15} & + & Prices for efficient sorters are decreasing & Economic \\
\hline & $\begin{array}{l}\text { Classical } \\
\text { Sorting }\end{array}$ & & \\
\hline 16 & - & $\begin{array}{l}100 \% \text { extraction of wheat and legume during classic sorting is impossible, since } \\
\text { some of the broken legume grains have the same size as some of the wheat grains }\end{array}$ & Technical \\
\hline 17 & + & $\begin{array}{l}\text { A 3-batch sorting is possible: easily separable wheat, easily separable pea, non- } \\
\text { separable wheat and pea mix }\end{array}$ & Technical \\
\hline 18 & - & $\begin{array}{l}\text { In case of } 3 \text { batches, the question of the use of the non-separable wheat and pea mix } \\
\text { still remains }\end{array}$ & Economic \\
\hline 19 & + & $\begin{array}{l}\text { The non-separable batch may be used for own consumption or for commercialization } \\
\text { in animal feed }\end{array}$ & Economic \\
\hline 20 & - & $\begin{array}{l}\text { The 3-batch solution is still costly, since it requires handling, several repetitions, and } \\
\text { leads to a lower financial benefit of the non-separable batch }\end{array}$ & Economic \\
\hline
\end{tabular}


defined as a pair $\mathrm{AS}=(\mathrm{A}, \mathrm{R})$ where $\mathrm{A}$ is a set of arguments and $\mathrm{R} \subseteq \mathrm{A} \times \mathrm{A}$ is an attack relation. An argument $\alpha$ attacks an argument $\beta$ if and only if $(\alpha, \beta) \in \mathrm{R}$. Hence, an argumentation system can be represented by a network whose nodes are arguments and oriented edges represent the attack relation between arguments.

For example, Figure 1 shows the argumentation system which formalizes the sub-debate on sorting options and derives from the information presented in Table 1. Two parts can be distinguished in the figure. The upper part of Figure 1 serves as a legend and provides color codes. On the left hand side two criteria are displayed: economic (green outline) and technical (purple outline). On the right hand-side a hierarchy of options is displayed: no sorting (white background color), sorting (yellow background), at harvest time (orange background), after harvest (blue background), classic (dotted background) and optical (dashed background). The options are organized in a hierarchical way that shows the chain of decisions that can be made by the selected actors.

The lower part of Figure 1 displays the argumentation system. Each argument is represented by an oval, labeled by its ID and a short title (refer to Table 1 for the details). The background color of the oval indicates which option the argument supports. The outline color of the oval indicates the criterion the argument refers to. Finally, the arrows represent attacks between arguments, that is to say, conflicts among them.

For instance, Argument 8 (on the left side of Figure 1) is labelled 'Growing market' and supports the "no sorting" option (white background) based on economic considerations (green outline). Argument 8 attacks Argument 1, which claims that there is no market for mixed grains and thus supports the sorting option (yellow background), also for economic reasons (green outline). In Figure 1, the group of arguments debating the "no sorting" option are gathered on the upper left side of Figure 1 (arguments 2, 3, 5 and 8); those debating the "sorting at harvest time" option are on the lower left

Figure 1. Argumentation system debating the sorting options
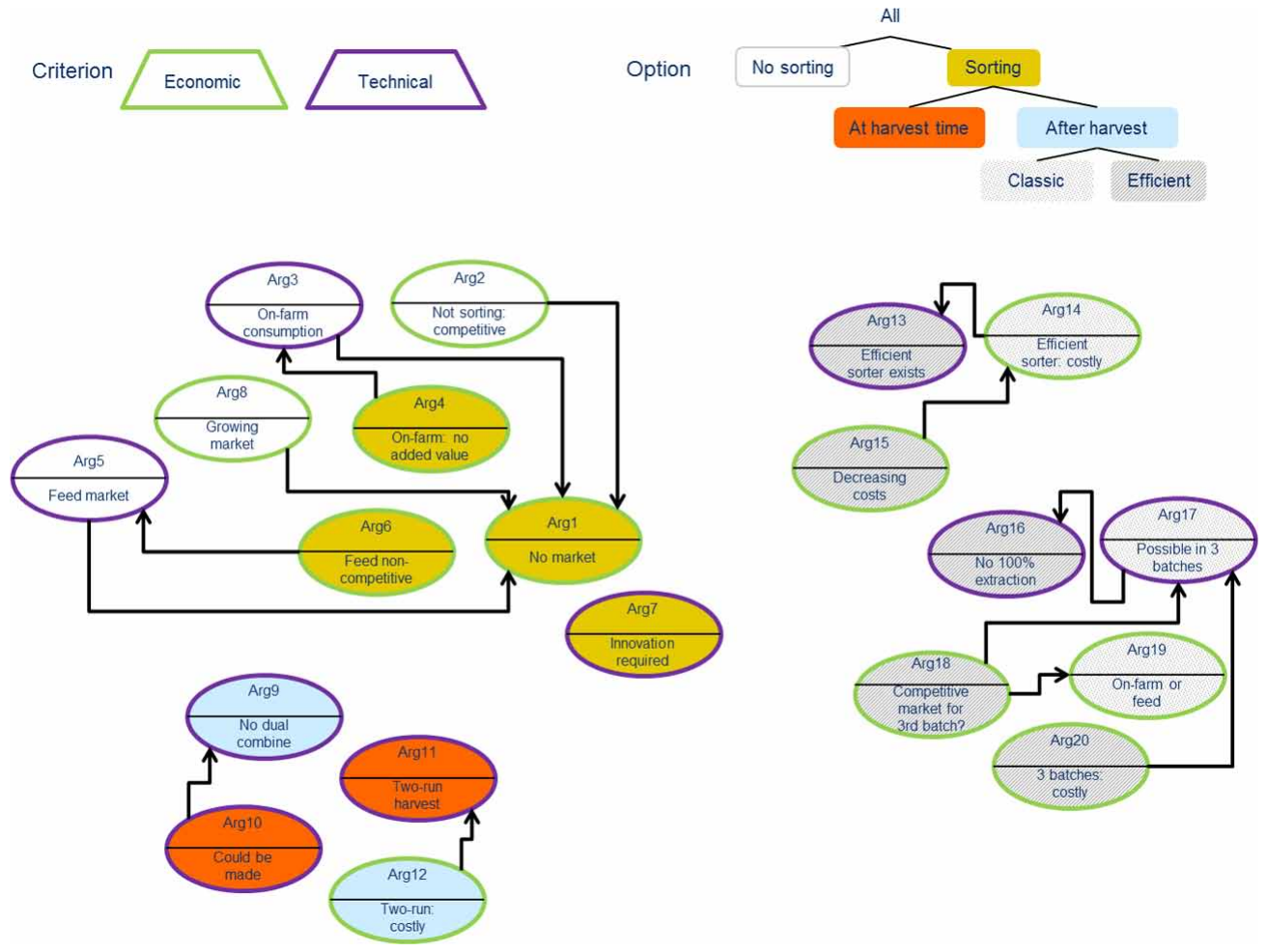
side of Figure 1 (arguments 10 and 11), and the arguments concerning the "after-harvest sorting", with the efficient and classic options, are depicted on the right side of Figure 1 (arguments 13 to 20).

Let us emphasize that in practice an argumentation system is seldom composed of a single network connecting all the arguments of the system. As you can see in the lower part of Figure 1 there are 6 networks of connected arguments, one being a single node (Argument 7). Let us also emphasize that our method enhances traditional argumentation system analysis by differentiating the arguments with respect to the options they support (displayed by the color code of the ovals in Figure 1) as well by identifying which criterion is supported by the argument. Hence, our representation of argument networks enables the analyst to choose which portion(s) of the argumentation system (i.e. argument sub-networks) should be analyzed given the objectives and scope of his/her study. For example, since our current study does not focus on technical innovation, the argument network corresponding to Argument 7 in Figure 1 is not relevant. Moreover, we are neither interested in the argument network (arguments 1 to 6 and 8) that addresses the options corresponding to the commercialization of the mixed grains. This is left for another study. Hence, we concentrate on options that consider grain sorting. When considering the argument sub-networks related to harvest-time sorting, we notice that the option corresponding to the use of dual combine harvesters (arguments 9 and 10) is not currently available to farmers and that the two phase harvest (arguments 11 and 12) is feasible but costly, and it is unlikely that farmers will practice it. Although it could be interesting to push further the study of this option, we decided to restrict our investigation to currently available technology for the after-harvest sorting. Consequently, we will analyze the argument sub-networks corresponding to the After-harvest-sorting options (efficient vs classic sorting) corresponding to arguments 13 to 20 .

\subsection{Reliable Arguments for Hypothesis Selection}

Going back to the formal argumentation model, we need to indicate that the analysis of an argument system AS is usually based on three essential assumptions: (1) AS is considered to be complete (i.e. we only consider the arguments composing AS); (2) the arguments which "have the last word", that is to say, arguments that have countered all their contradictors or are not attacked, are considered as the most reliable ones, and (3) coherent decisions are provided by groups of arguments that are both reliable and without contradictions with one another. Such sets of so-called "accepted" arguments correspond to consistent points of view and are called "extensions" (Dung, 1995). Different semantics for this notion have been proposed. For the purpose of this paper, we only recall the "preferred" semantics.

Let $\mathrm{B} \subseteq \mathrm{A}$. Then:

- $\quad B$ is conflict-free if and only if $\nexists \alpha i, \alpha j \in B$ such that $(\alpha i, \alpha j) \in R$;

- B defends an argument $\alpha i \in B$ if and only if for each argument $\alpha j \in A$, if ( $\alpha j$, $\alpha i) \in R$, then $\exists$ $\alpha \mathrm{k} \in \mathrm{B}$ such that $(\alpha \mathrm{k}, \alpha \mathrm{j}) \in \mathrm{R}$;

- a conflict-free set B of arguments is admissible if and only if B defends all its elements;

- a preferred extension is a maximal (with respect to set inclusion) admissible set of arguments;

- an argument is skeptically accepted if it is in all extensions, credulously accepted if it is in at least one extension and rejected if it is not in any extension.

We applied this consistency checking method to the argument sub-networks corresponding to the After-harvest-sorting options, using the Aspartix tool (https://www.dbai.tuwien.ac.at/proj/ argumentation/systempage/). The corresponding argumentation system is loaded using the dedicated syntax to declare the list of arguments and the list of attacks as shown in Table 2.

The computation result provides the following unique preferred extension:

$\{\operatorname{Arg} 13, \operatorname{Arg} 15, \operatorname{Arg} 16, \operatorname{Arg} 18, \operatorname{Arg} 20\}$. 
Table 2. List of arguments and attacks in Aspartix format

\begin{tabular}{|l|l|}
\hline \multicolumn{1}{|c|}{ List of arguments } & \multicolumn{1}{c|}{ List of attacks } \\
\hline $\arg (\operatorname{Arg} 13)$. & att(Arg14,Arg13). \\
$\arg (\operatorname{Arg} 14)$. & att(Arg15,Arg14). \\
$\arg (\operatorname{Arg} 15)$. & att(Arg17,Arg16). \\
$\arg (\operatorname{Arg} 16)$. & att(Arg18,Arg17). \\
$\arg (\operatorname{Arg} 17)$. & att(Arg19). \\
$\arg (\operatorname{Arg} 18)$. & \\
$\arg (\operatorname{Arg} 19)$. & \\
$\arg (\operatorname{Arg} 20)$. & \\
\hline
\end{tabular}

Since the extension is unique, skeptically and credulously accepted arguments are identical. These accepted arguments are thus retained as reliable: 13, 15, 16, 18, and 20, that is, those in favor of efficient sorting. Indeed, these arguments are either not contradicted (e.g. Argument 15: decreasing cost of efficient sorters) or defended by other arguments.

Among the sub-sets of arguments identified as reliable, the analyst will now identify: 1) if the situation referred by each argument can possibly evolve in the future, and under which circumstances, and 2) if it can be quantified by variables, and which ones. This step allowed us to select, within reliable arguments, Argument 15, since: 1) it refers to the evolution of efficient sorter prices in the future, and 2) this price evolution will allow us to make hypotheses on the possible values of a variable directly related to the interest of efficient sorters for farmers, namely the sorting cost expressed in $€ . t^{-1}$ of, which impacts the computation of the farmer half-net margin. This is developed in next Section.

\subsection{SD Model Development and Reference Scenarios}

Systems Dynamics (Forrester, 1971) is a mathematical modeling technique which allows for analysing the temporal evolution of systems defined by a large number of interdependent variables. One of the variables considered by the system is thus time. The other variables are defined according to the problem to be solved.

We can distinguish three main categories of variables (apart from time):

- Constants: Their value does not vary over time. They are depicted by black-arrowed circles in the graphical model (see Figure 2);

- Stock Variables: They represent the accumulation of a quantity over time and thus correspond to an integral-type function. They are depicted by squares;

- The other variables (general case) are depicted by circles.

Arrows indicate a variable is involved in the calculation of the following one.

To create a simple, qualitative and significant model of the farmer's operating situation, we chose to consider a compound view of the financial aspects of the farming operations, using the farmer's half-net margin. It is defined as the difference between incomes and expenses:

Half-net margin = Incomes - Expenses, where:

- Incomes Include: (1) revenues from products' sales, (2) public aids, in particular provided by the Common Agricultural Policy (CAP).

- Expenses Include: (1) input costs: seeds, fertilisers and pesticides; (2) mechanization costs including all the operations from soil preparation to harvest (implements, amortization, maintenance and repair, fuel and labour costs). 
Figure 2. Sole cropped wheat Neodur simulation

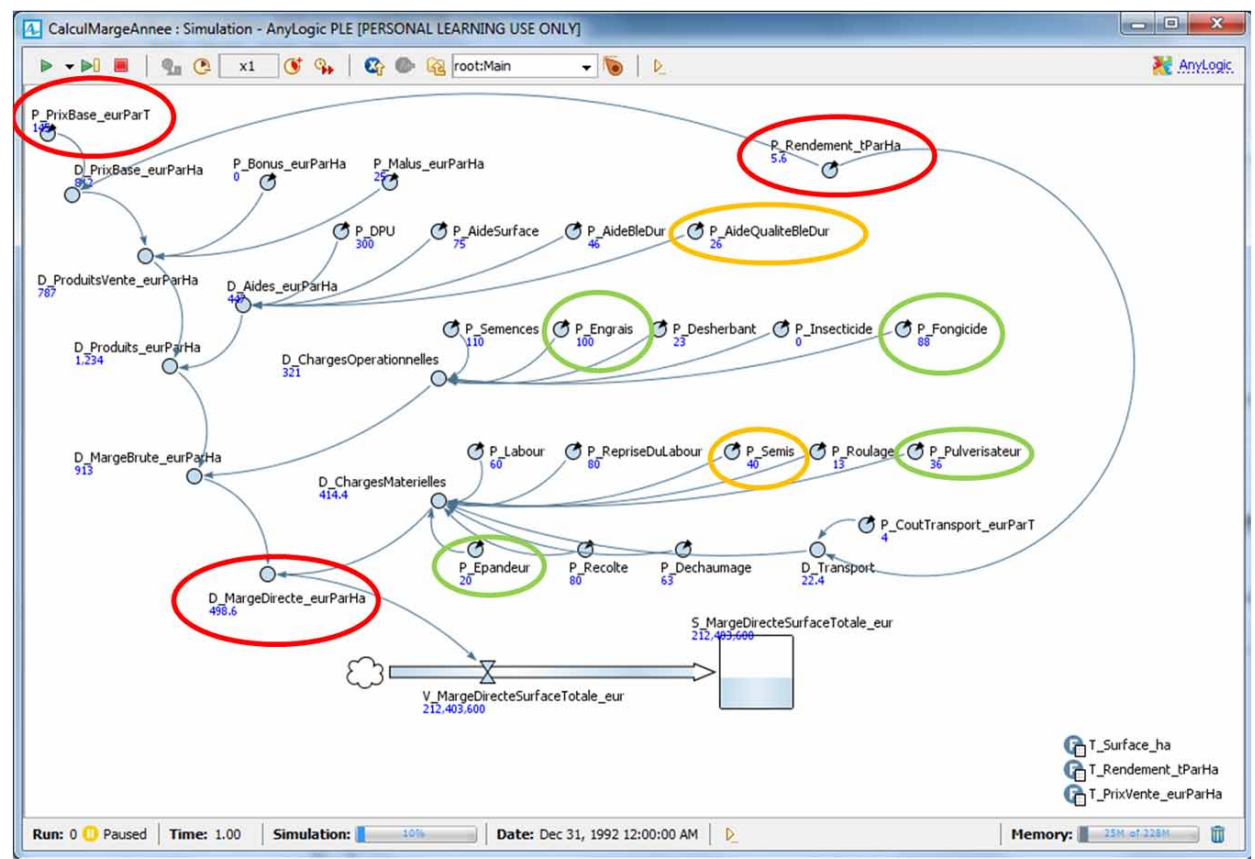

Figures 2 and 3 display the graphical representation of the SD model of the farmer's half-net margin that we implemented using the Anylogic software (www.anylogic.com). They respectively show the resulting state of the simulations for the case one-year culture of sole crop Durum wheat (Neodur variety) and for the case of one-year Durum wheat-Pea intercropping. We call these simulations 'reference scenarios' because they will be used as a reference in the next stage of our method in which we will assess and compare What-if scenarios. Comparing these two scenarios from an economic point of view, intercropping appears as being clearly less efficient than the sole Durum wheat crop, with an half-net margin of the intercrop of only $220 €$. ha $^{-1}$ while the half-net margin of the sole crop wheat is $522 € \cdot$ ha $^{-1}$. This difference can be explained when considering the values assigned to the SD model variables in these scenarios: (1) the yield gap leading to a sale of products of the intercrop of only $618 € . \mathrm{ha}^{-1}$ compared to the $812 € . \mathrm{ha}^{-1}$ of the sole cropped wheat and (2) the material cost which was $638 € . \mathrm{ha}^{-1}$ for the intercrop compared to $415 € . \mathrm{ha}^{-1}$ for the sole cropped wheat due to the 222 $€$.ha $\mathrm{a}^{-1}$ extra charge for intercrop grain sorting. Conversely, the operational costs were only $180 € . \mathrm{ha}^{-1}$ for the intercrop compared to the $321 € \cdot$ ha $^{-1}$ of the sole cropped wheat.

To conclude this comparison of our two reference scenarios, it appears that while intercropping seems to be an interesting agronomic option for low input systems, its economic efficiency is strongly reduced by the sorting costs needed to separate the grains if the farmer aims at selling his grains for human consumption.

\subsection{What-If Scenario Analysis}

In this What-if analysis we aim at exploring how changing some conditions may influence the outcomes of applying either cultural alternative. We first consider the case in which farmers choose the efficient sorting option to set the initial hypothesis corresponding to Argument 15.

- Hypothesis 0: 'costs of optical sorters will decrease in the future'. 
Figure 3. Durum wheat-winter Pea intercropping simulation

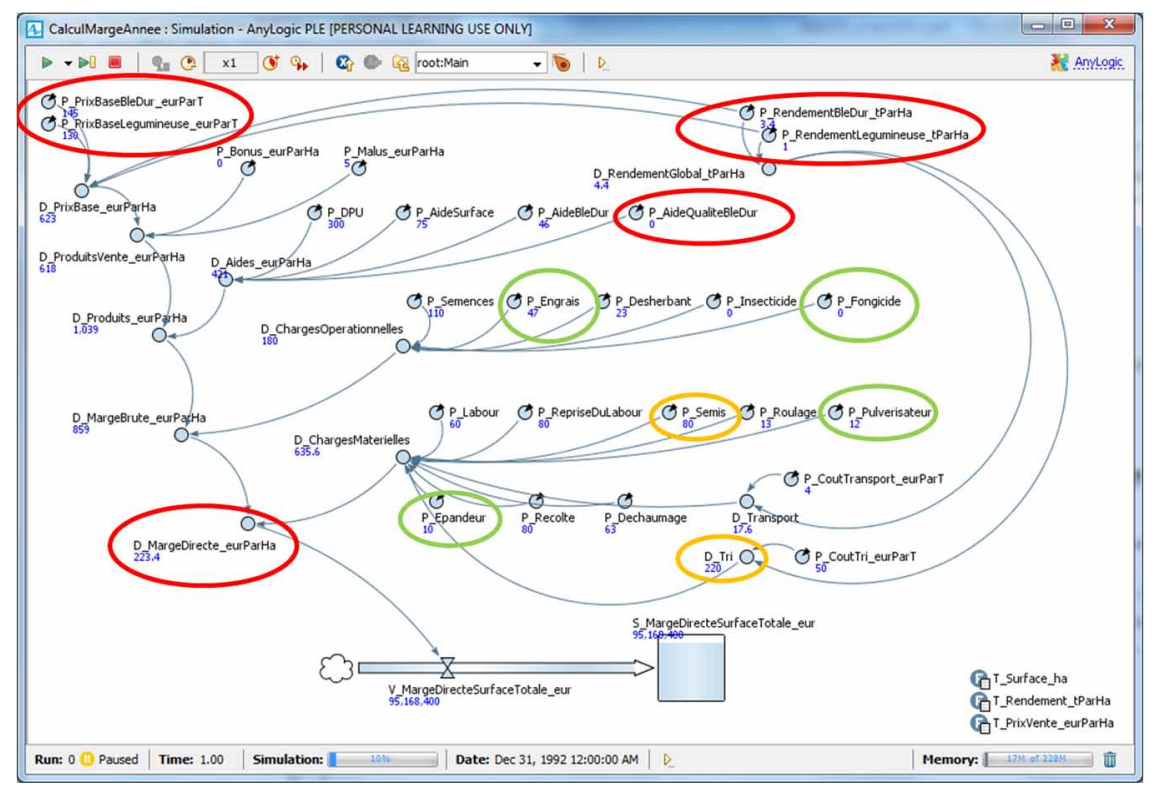

- Scenario 0: This hypothesis implies a change in the SD model: The Sorting costs parameter is reduced from $50 € \cdot$ ha $^{-1}$ to $10 € \cdot$ ha $^{-1}$. We run the simulations for the two cultural strategies and obtained the column of results displayed in Figure 4 named 'Scenario 0'.

We observe a significant enhancement of the intercropping strategy. Reducing the cost for grain separation improves the half-net margin of the intercrop by $178 € \cdot$ ha $^{-1}$ leading to a half-net margin of $398 €$. ha $^{-1}$ compared to $522 €$. ha $^{-1}$ for the sole cropped wheat. But this would be still insufficient to motivate farmers to choose the intercropping strategy.

This is where setting What-if hypotheses might help to expand the debate by allowing the exploration of alternatives triggered by external forces such as the market and public authorities. In our study we explore two What-if hypotheses.

- What-if Hypothesis 1 - Input-dissuasive measures: 'Input costs (fertilizers and crop protection products) will increase in the future'

- Scenario 1: This scenario tests the hypothesis of increased input costs and aims at determining which increase of input costs would lead to similar half-net margins for sole Durum wheat and for intercropping, all other things remaining equal.

The SD model must be adjusted. It was determined that chemical input prices must be multiplied by 1.88 leading to a decrease of the half-net margin of the intercrop by $62 €$. ha $^{-1}$ while that of the sole cropped wheat is reduced by $186 € . \mathrm{ha}^{-1}$ since this system uses more chemicals. Finally, both systems reach a final half-net margin of $337 € \cdot \mathrm{ha}^{-1}$. This is displayed in Figure 4 in the column named 'Scenario 1'.

- What-if Hypothesis 2 - Intercropping-incentive measures: 'Availability of new public aids supporting the adoption of intercropping' 
- Scenario 2: This scenario tests the hypothesis of public aids through intercropping incentive measures and aims at determining which level of aids would lead to similar half-net margins for sole Durum wheat and for intercropping, all other things remaining equal.

Again, the SD model must be adjusted. It was determined that public aids supporting the adoption of intercropping must be of $124 € . \mathrm{ha}^{-1}$ in order to rise the half-net margin of the intercrop to $522 €$.ha $^{-1}$ while the half-net margin of the sole cropped wheat remains unchanged at $522 €$.ha $^{-1}$.

Intermediate remark. These two scenarios do not appear to be reasonable and a compromise between incentive and dissuasive measures can be sought for. This led us to raise a third hypothesis.

- What-if Hypothesis 3 - Correlation of Public Aids and Chemical CIC: correlate the amount of public aid and the chemical input cost (CIC)

- Scenario 3: In this scenario we computed how the public aid (PA) can be correlated to the chemical input cost (CIC) in order to obtain the same half-net margin between the intercrop and the sole cropped wheat. We obtained the equation: $\mathrm{PA}=-141 * \mathrm{CIC}+265$. This mean that if the CIC is equal to 1 (current situation) then PA must be of $124 € . \mathrm{ha}^{-1}$ as indicated in scenario 2. Conversely, if CIC is equal to 1.88 (scenario 1) then PA could be null.

This result can help policy makers determine some threshold which could be a compromise between the amount of public aid to support the adoption of intercropping and a reasonable increase of the chemical input cost (CIC). To illustrate such a compromise we set a 1.44 increase of chemical input prices along with a specific subsidy for intercropping of $62 € \cdot \mathrm{ha}^{-1}$. In this third scenario the halfnet margin of the two systems will be of $430 € . \mathrm{ha}^{-1}$ (see last column in Figure 4 named 'Scenario 3).

\subsubsection{Comparison of the What-If Scenarios}

Figure 4 displays in a synthetic way the comparison of all the scenarios that have been explored in this study, thanks to the use of the SD model and simulations. The diagrammatic comparison of the scenarios' end-states can be easily understood by the different involved stakeholders. It appears clearly that finding a compromise in the form of scenario 3 is a promising avenue that public authorities may explore if they want to promote intercropping.

\section{CONCLUSION}

In this paper we proposed a method combining argumentation and simulation to analyze the issues of intercropping adoption versus sole crops, in low input systems. We presented a detailed analysis of a subset of arguments debating the relevance of different grain sorting options, and highlighting concerns about the cost of the sorting step in intercropping. Based on this analysis, we tested two scenarios in which reduced sorting costs are taken as a hypothesis. The first scenario simulates dissuasive measures regarding the use of farm inputs. The second scenario simulates incentive measures regarding the adoption of intercropping. To reach similar economic benefits for farmers in intercropping and sole crops, the first scenario concludes on input prices increased by a factor 1.88 , and leads to very reduced half-net margins. In contrast, the second scenario concludes on a high aid levels to support the competitiveness of intercropping of $124 € . \mathrm{ha}^{-1}$.

The comparison of the outcomes of these scenarios aims at informing farmers groups and public policy makers of the benefits and drawbacks of intercropping and at suggesting that a compromise might be found between incentive and dissuasive measures. A perspective of this work is to couple 
Figure 4. Half-net margin for the scenarios tested: (1) initial simulations; (2) scenario 0: reduced sorting costs to $10 €$.ha ${ }^{-1}$, (3) scenario 1: reduced sorting costs to $10 €$ ha $^{-1}$ and chemical input costs multiplied by 1.88 ; (4) scenario 2: reduced sorting costs to $10 €$.ha ${ }^{-1}$ and bonus for intercropping of $124 €$. ha $^{-1}$ and (5) scenario 3 : reduced sorting costs to $10 €$.ha- ${ }^{-1}$, chemical input costs multiplied by 1.44 and bonus for intercropping of $62 €$.ha-1

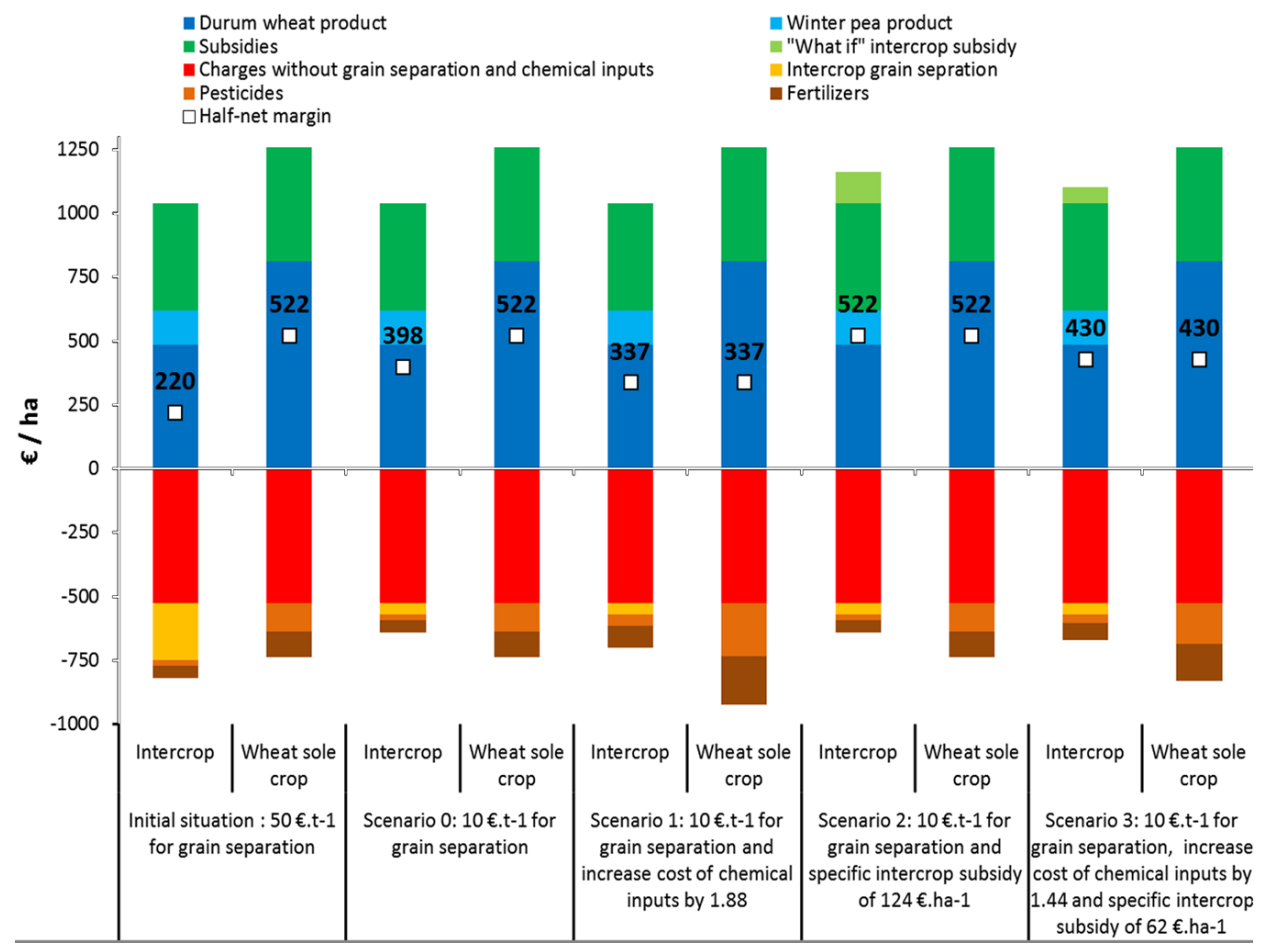

the approach with an agronomic model to test other kinds of scenarios, including environmental impacts but also the rotation scale.

As mentioned in the paper, we used widely available software solutions toapply our method, namely the Aspartix software tool for argument/attack representation and extension computation, and the Anylogic platform for system dynamic simulations. Developing a complete software framework to support the proposed approach was not a goal of our project. However, that is an interesting perspective for further research work, especially to propose a framework that integrates argumentation and simulation tools, such as system dynamics and agent-based simulation.

To conclude, let us emphasize that computational models are increasingly used to assist in developing, implementing and evaluating public policies (Gilbert et al. 2018). These authors indicate that policy models can have an important place in the policy process because they allow policy makers to experiment in a virtual world. We hope that the approach proposed in this paper will foster new interest of policy makers and of the various stakeholders involved in the agri-food chain in the use of computational modeling when devising new policies. The principled use of relatively simple argumentation models and of modeling and simulation techniques (such as System Dynamics) helps identifying some key variables and parameters, as well as their interactions, that are meaningful to the involved stakeholders. The simulations of the temporal evolution of these variables under different hypotheses (setting the values of certain parameters) results in different scenarios. The scenarios' outcomes can be assessed, compared and synthetically/visually presented to stakeholders and policy makers in order to help them 
to: 1) better understand the attended situation; 2) to share a common vision of the situation, of the available actions/options, of the arguments put forward by the involved parties; and 3) the consequences of choosing each option/action. Hence, this is a way to increase their situation awareness and better inform the collaborative decision-making process.

\section{ACKNOWLEDGMENT}

This manuscript is an extended version of an EFITA submission. 


\section{REFERENCES}

Adams, M. J., Tenney, Y. J., \& Pew, R. W. (1995). Situation awareness and the cognitive management of complex systems. Human Factors, 37(1), 85-104. doi:10.1518/001872095779049462

Amgoud, L., \& Prade, H. (2009). Using arguments for making and explaining decisions. Artificial Intelligence, 173(3-4), 413-436. doi:10.1016/j.artint.2008.11.006

Pelzer, E., Bedoussac, L., Corre-Hellou, G., Jeuffroy, M. H., Métivier, T., \& Naudin, C. (2014). Association de cultures annuelles combinant une légumineuse et une céréale: Retours d'expériences d'agriculteurs et analyse. Innovations Agronomiques, 40, 73-91.

Balmann, A., Dautzenberg, K., Happe, K., \& Kellermann, K. (2006). On the dynamics of structural change in agriculture. Outlook on Agriculture, 35(2), 115-121. doi:10.5367/000000006777641543

Baroni, P., \& Giacomin, M. (2009). Semantics of Abstract Argument Systems. In G. Simari \& I. Rahwan (Eds.), Argumentation in Artificial Intelligence (pp. 25-44). Boston, MA: Springer. doi:10.1007/978-0-387-98197-0_2

Bedoussac, , LJournet, E.-P., Hauggaard-Nielsen, H., Naudin, C., Corre-Hellou, G., Jensen, E. S., \& Justes, E. et al. (2015). Ecological principles underlying the increase of productivity achieved by cereal-grain legume intercrops in organic farming. A review. Agronomy for Sustainable Development, 35(3), 911-935. doi:10.1007/ s13593-014-0277-7

Bedoussac, L., Tribouillois, H., Plaza-Bonilla, D. \& Justes, E. (2016). Designing and evaluating arable systems Cash and cover crop legumes in sole crop and intercrop to improve nitrogen use efficiency. In 14th European society for agronomy congress, Edinburgh, UK, September 5-9.

Bedoussac, L., \& Justes, E. (2010). The efficiency of a durum wheat-winter pea intercrop to improve yield and wheat grain protein concentration depends on $\mathrm{N}$ availability during early growth. Plant and Soil, 330(1-2), 19-35. doi:10.1007/s11104-009-0082-2

Besnard, P., \& Hunter, A. (2008). Elements of argumentation (Vol. 47). Cambridge: MIT Press. doi:10.7551/ mitpress/9780262026437.001.0001

Bourguet, J.-R., Thomopoulos, R., Mugnier, M.-L., \& Abécassis, J. (2013). An artificial intelligence-based approach to deal with argumentation applied to food quality and public health policy. Expert Systems with Applications, 40(11), 4539-4546. doi:10.1016/j.eswa.2013.01.059

Burgess, H., \& Spangler, B. (2003) Consensus Building. In G. Burgess \& H. Burgess (Eds.), Beyond Intractability. Conflict Information Consortium, University of Colorado, Boulder.

Campbell, M., \& C., (2004). Building a common table: The role for planning in community food systems. Journal of Planning Education and Research, 23(4), 341-355. doi:10.1177/0739456X04264916

Casey, F., Schmitz, A., Swinton, S., \& Zilberman, D. (Eds.). (1999). Flexible Incentives for the Adoption of Environmental Technologies in Agriculture (Vol. 17). Springer Science \& Business Media. doi:10.1007/97894-011-4395-0

Chambers, R. G. (2002) Information, incentives, and the design of agricultural policies. In Handbook of Agricultural Economics (Vol. 2, Ch. 34, pp. 1751-1825).

Croitoru, M., Buche, P., Chanormordic, B., Fortin, J., Jones, H., Symeonidou, D., \& Thomopoulos, R. (2016). A proposal for modelling agrifood chains as multi-agent systems. In E. Hüllermeier, R. Kruse, \& F. Hoffmann (Eds.), Information Processing and Management of Uncertainty in Knowledge-Based Systems (pp. 498-509). doi:10.1007/978-3-319-40596-4_42

Dung, P. M. (1995). On the acceptability of arguments and its fundamental role in nonmonotonic reasoning, logic programming and n-person games. Artificial Intelligence Journal, 77(2), 321-357. doi:10.1016/00043702(94)00041-X

Endsley, M. R. (1995). Toward a theory of situation awareness in dynamic systems. Human Factors, 37(1), 32-64. doi:10.1518/001872095779049543 
Filippi, M., \& Chapdaniel, A. (2016) A new modeling approach for adding value to agri-food chains. In Proceedings of the 149th EAAE Seminar 'Structural change in agri-food chains: new relations between farm sector, food industry and retail sector, Rennes, France, October 27-28.

Forrester, J. (1971). Counterintuitive behavior of social systems. Technology Review, 73(3), 52-68.

Ghaffarzadegan, N., Luneis, J., \& Richardson, G. P. (2011, January-March). How small System Dynamics models can help the public policy process. System Dynamics Review, 27(1), 22-44.

Gilbert, N., Ahrweiler, P., Barbrook-Johnson, P., Preethi Anarsimhan, K., \& Wilkinson, H. (2018). Computational modeling of public policy: reflections on practice. JASSS, 21(1).

Gray, B. (1989). Collaborating: Finding Common Ground for Multiparty Problems. San Francisco: Jossey-Bass Publishers.

Handayati, Y., Simatupang, T. M., \& Tomy Perdana, T. (2015). Agri-food supply chain coordination: The stateof-the-art and recent developments. Logistic Research, 8(5).

Hirsch, G. B., Levine, R., \& Miller, R. L. (2010). Using System Dynamics modeling to understand the impact of social change initiatives. American Journal of Community Psychology, 39(3-4), 239-253. doi:10.1007/ s10464-007-9114-3 PMID:17406970

Marshall, D. A., Burgos-Liz, L., Ijzerman, M. J., Crown, W., Padula, W. K., Wong, P. K., \& Osgood, N. D. et al. (2015). ISPOR Task Force Report, Selecting a dynamic simulation modeling method for Health Care delivery research. Value in Health, 18(2), 147-160. doi:10.1016/j.jval.2015.01.006 PMID:25773550

Ouerdane, W., Maudet, N., \& Tsoukias, A. (2010). Argumentation Theory and Decision Aiding. In J. Figueira, S. Greco \& M. Ehrgott (Eds.), Trends in Multiple Criteria Decision Analysis (pp. 177-208). Springer. doi:10.1007/978-1-4419-5904-1_7

PerfCom Project. (2012). Les cultures associées céréale/légumineuses en agriculture "bas intrants" dans le sud de la France. Retrieved from http://www6.montpellier.inra.fr/systerra-perfcom/

Stave, K. A., \& Kopainsky, B. (2015). A system dynamics approach for examining mechanisms and pathways of food supply vulnerability. Journal of Environmental Studies and Sciences, 5(3), 321-336. doi:10.1007/ s13412-015-0289-X

Thomopoulos, R., Croitoru, M., \& Tamani, N. (2015). Decision Support for Agri-Food Chains: A Reverse Engineering Argumentation-Based Approach. Ecological Informatics, 26(2), 182-191. doi:10.1016/j. ecoinf.2014.05.010

van Bruggen, J. M., Boshizen, H. P. A., \& Kirschner, P. A. (2003), A cognitive framework for cooperative problem solving with argument visualization, In Kirschner, Shum, Buckingham et al. (Eds.), Visualizing Argumentation (pp. 25-47). Springer Verlag.

Walton, D., \& Macagno, F. (2015). A classification system for argumentation schemes. Argument \& Computation, 6(3), 219-245. doi:10.1080/19462166.2015.1123772 
Rallou Thomopoulos, HDR (habilitation to conduct research groups and PhDs), has been INRA Research Scientist since 2004, permanent member and co-creator of the GraphIK lab at INRIA. She has dual skills in computer science and agri-food sector. Research topics are knowledge representation and decision support, argumentation systems. Guest Research Scientist at Laval University (Quebec, Canada) from 2015-2016; previously a 5 year Assistant Professor at AgroParisTech.

Bernard Moulin is Full Professor at Laval University in the Department of Computer Science and Software Engineering, affiliated with the Research Center in Geomatics and the Research Center on Big Data. For 12 years, ending in 2012, he has led several projects funded by Geoide, the Canadian Network of Centers of Excellence in Geomatics, and governmental and industrial partners. His research had a broad scope with a focus on knowledge representation, intelligent system development, applications of artificial intelligence techniques in geomatics, multiagent and population-based geo-simulation. In all those domains a special emphasis was put on the creation of system analysis and design methods.

Laurent Bedoussac carries out his researches at the French National Institute for Agricultural Research in Toulouse (INRA, France). He is also assistant-professor at the National School of Agricultural (ENSFEA) teaching in agronomy, viticulture and horticulture. Laurent Bedoussac defended his PhD in september 2009 entitled "Analysis of the functioning and efficiency of Durum Wheat-Winter Pea and Durum Wheat-Winter Faba Bean intercrops in order to design cropping systems" which received the "Leopold Escande Award" of the National Polytechnic Institute of Toulouse. He published 4 book's chapters and 11 papers in international journals dealing with intercrops which last one is a review intituled "Ecological principles underlying the increase of productivity achieved by cerealgrain legume intercrops in organic farming. A review published in Agronomy for sustainable development. While intercrops are his main area of expertise, he also developed knowledge in farming systems design, agronomy production, crop physiology, ecology, breeding and market research in cereals and legumes. Laurent Bedoussac altogether with Eric Justes (senior researcher at INRA, agronomist modeler for soil-crop systems in interaction with $\mathrm{N}$ and water cycles) - his PhD promoter - have developed an extensive network of scientists within France working on cropping system design in low input farming and intercrops evaluation in collaborations with technical institutes and organic farmers. They have also established a diverse range of overseas collaborative research for intercrop topics in particular with Spain, Tunisia and Denmark and with others teams in France (INRA Paris Grignon and ESA Angers). 